\title{
PROXY RECORDS OF QUATERNARY CLIMATE
}

\author{
(Abstract)
}

by

John Imbrie

(Department of Geological Sciences, Brown University, Providence, Rhode Island 02912-1846, U.S.A.)

Geologic records provide important constraints on our ideas about the behavior of Quaternary ice sheets. Each type of record is a proxy sensing system that has its own advantages and limitations. Three of these sensing systems (glacial geology, palynology, and marine micropaleontology) are particularly valuable because they provide information about the spatial patterns of global $\mathrm{climate}$. By mapping and dating terminal moraines, glacial geologists provide information about the extent of ice at particular times in the past. Unfortunately, information of this kind is available only at a few discrete times. By mapping variations in fossil pollen, palynologists in the Cooperative Holocene Mapping Project (COHMAP) project have inferred the distribution of atmospheric fronts winds, and air masses at intervals of about $2 \mathrm{ka}$ over the past $18 \mathrm{ka}$ with considerable accuracy. Inferences about past temperature and precipitation have larger uncertainties, but can be compared with simulations of general circulation models. By mapping variations in fossil plankton and sediment chemistry, marine micropaleontologists in the Climate: Long-range Interpretation, Mapping and Prediction (CLIMAP) project have inferred the global distribution of fronts currents, and water masses in the surface ocean at the last glacial maximum with considerable accuracy. Although inferences about temperature and salinity have larger uncertainties, these uncertainties can be narrowed by comparing inferences from different biological groups, and by comparing these inferences with. estimates based on oxygen-isotope measurements.

Secure inferences about variations in oceanic deep and bottom waters have proved more difficult to obtain, but much progress is being made by combining three types of information derived from benthic foraminifera: variations in oxygen and carbon isotope ratios, variations in cadmium content, and variations in faunal composition. It is now quite clear that North
Atlantic Deep Water (NADW) production was much reduced at the last glacial maximum, but how much this reduction was and what the sites and modes of deep-water production were at that time are matters still under investigation.

The stratigraphic record of the deep sea is of particular importance because it provides a continuous set of observations capable of monitoring the behavior of climate over the entire Quaternary (and beyond). One subset of these data ( $\delta^{180}$ variations) is of particular interest because it yields inferences about the global volume of glacial ice. Recent results of the SPECMAP project* will be described which use observations of $\delta^{180}$ in five deep-sea cores to develop a time scale for the past $800 \mathrm{ka}$ that is believed to be accurate with in $\pm 5 \mathrm{ka}$. Displayed on this time scale, the isotopic variations are phase-locked $\left( \pm 15^{\circ}\right)$ and strongly coherent $(>0.9)$ with orbital variations, not only at the main periods of precssion ( 19 and $23 \mathrm{ka}$ ) and obliquity (41 ka), but also in the $100 \mathrm{ka}$ eccentricity band. This statistical evidence of a close relationship between the timevarying amplitudes of orbital forcing and the timevarying amplitudes of the isotopic response implies that orbital variations are the main primary cause of the succession of glacial and interglacial ages during the late Pleistocene. Close scrutiny of the isotopic phase spectrum suggests that a climate resonance operates at periods near $100 \mathrm{ka}$. The possibility that atmosphere-cryosphere-lithosphere feedbacks yield self-oscillation tendencies at these low frequencies is therefore worth further study.

*SPECMAP is a multi-institutional research project, sponsored by the US National Science Foundation, which maps variations in ocean spectra over a frequency range from $10^{-5}$ to $10^{-3}$ cycles $\mathrm{a}^{-1}$. 